\title{
Avaliação da implementação da Educação Sexual em contexto escolar, na região do Algarve - A perspetiva de atores educativos responsáveis pela Educação para a Saúde/Educação Sexual
}

\author{
Liliana Paulosi \& Sandra T. Valadasii \\ Universidade do Algarve, Portugal
}

\begin{abstract}
Resumo
O presente estudo assume-se como um estudo de caso, insere-se no paradigma interpretativo/qualitativo e pretendeu avaliar a implementação da Educação Sexual (ES) no Algarve. Realizaram-se entrevistas semidiretivas a oito coordenadores da Educação para a Saúde (EpS)/ES e a um diretor de agrupamento de escolas (AE). Os resultados indicaram que a ES foi integrada nos projetos educativos de todos os $A E$, sendo que os $A E$ situados em concelhos com menos residentes apresentaram um percurso mais próximo das recomendações da lei. Foram nomeados professores-coordenadores para a EpS/ES e apenas um AE não tem o gabinete de apoio a funcionar. $A$ disciplina de Ciências Naturais foi identificada como sendo a mais interveniente na ES. O aumento e a consolidação dos conhecimentos foram objetivos privilegiados numa vertente de prevenção. O pouco apoio do Ministério da Educação e Ciência e a falta de formação, de experiência e de à-vontade dos docentes nesta área foram apontados como limitações no processo de implementação da ES.
\end{abstract}

Palavras-chave

Educação Sexual; Avaliação; Implementação; Coordenadores; Professores; Diretor 


\section{Introdução}

Tendo em conta as ligações da sexualidade às dimensões da identidade pessoal e das relações interpessoais, a Educação Sexual (ES) precisa de ser concetualizada de forma holística, englobando as dimensões biológica, psicoafetiva, sociocultural, relacional e ética, ligadas e dependentes entre si (Frade, Marques, Alverca, \& Vilar, 2006; López \& Fuertes, 1999; Matos, Reis, Ramiro, Ribeiro, \& Leal, 2014). Também a Organização Mundial de Saúde [OMS] (2010), nas últimas décadas, tem reforçado a necessidade de implementar estratégias efetivas que promovam a vivência segura e feliz da sexualidade, realçando o papel da ES.

De acordo com o Ministério da Educação - Grupo de Trabalho de Educação Sexual (ME-GTES) (2005), a ES é o "processo pelo qual se obtém informação e se formam atitudes e crenças acerca da sexualidade e do comportamento sexual" (p. 6). Considerando que a escola é onde as crianças e os jovens passam grande parte do seu tempo (United Nations Educational, Scientific and Cultural Organization - UNESCO, 2009), a concretização da ES em contexto escolar parece ser essencial (Frade et al., 2006). A escola possui, também, uma vertente de formação pessoal e social que atua na promoção de competências e capacidades para a resolução dos problemas quotidianos (Canário, 2005), devendo ser considerada como um contexto importante para possibilitar o aumento de conhecimentos na área da sexualidade e para a promoção de atitudes e comportamentos adequados (ME-GTES, 2007b).

As abordagens educativas no âmbito da sexualidade e, consequentemente, da ES, são diversificadas e foram surgindo em função da evolução e transformação do próprio conceito de ES. Desta forma, os diferentes modelos de ES caracterizam-se por terem distintos quadros de valores que orientam as práticas educativas, diferentes conteúdos e metodologias pedagógicas (Vaz, Vilar, \& Cardoso, 1996; Vilaça, 2006). Vaz et al. (1996) consideraram quatro modelos de ES que, apesar de assumirem designações diferentes, se coadunam com os modelos propostos por López (1990). Em Portugal, o modelo impositivo conservador, o qual justifica a finalidade da sexualidade como sendo meramente reprodutiva, teve grande ênfase, dado o peso da Igreja na nossa sociedade. Também o modelo médico-preventivo, amplamente divulgado em Portugal nos anos 90, no âmbito da Rede de Escolas Promotoras de Saúde (REPS), se tornou 
característico das intervenções de muitas instituições de saúde em meio escolar, visando a prevenção do aborto, das Infeções Sexualmente Transmissíveis (IST) e da gravidez na adolescência (López \& Oroz, 1999). O estudo de Matos et al. (2014) permitiu perceber que este modelo continua a ser o mais praticado nas escolas portuguesas. Ainda assim, o modelo de desenvolvimento pessoal é considerado o mais atual e pertinente, pois aborda a sexualidade nas suas várias vertentes (Ramiro, Reis, Matos, Diniz, \& Simões, 2011; Vilar, 2002).

Em Portugal, a primeira lei a contemplar a ES em contexto escolar foi aprovada em 1984 (Lei n. ${ }^{\circ}$ 3/84), e, em 1999, a Lei n. ${ }^{\circ} 120 / 99$ reafirmou a necessidade de reforçar as garantias do direito à saúde reprodutiva. Em 2000, a Escola foi reconhecida, através do Decreto-Lei n. ${ }^{\circ}$ 259/2000, como entidade competente para integrar estratégias de promoção e Educação para a Saúde (EpS), incluindo a ES nos currículos dos ensinos básico e secundário (Decreto-Lei n. ${ }^{\circ}$ 259/2000). Com a reforma curricular de 2001, a ES pôde ser abordada no ensino básico, nas áreas curriculares não disciplinares (ACND): Formação Cívica, Estudo Acompanhado e Área de Projeto, estabelecidas pelo Decreto-Lei n. ${ }^{\circ}$ 6/2001. Somente em 2009 a Lei n. ${ }^{\circ}$ 60/2009 estabeleceu a aplicação da ES nos estabelecimentos do ensino básico e do ensino secundário, em resultado das recomendações presentes nos vários documentos elaborados pelo GTES (ME-GTES, 2005, 2007a, 2007b). Desta forma, consagraram-se as bases gerais do regime de implementação da ES em contexto escolar, "conferindo-Ihe o estatuto e a obrigatoriedade, com uma carga horária adaptada e repartida por cada nível de ensino, especificada por cada turma e distribuída de forma equilibrada pelos diversos períodos do ano letivo" (Portaria n. ${ }^{\circ}$ 196-A/2010, p. 1170-2), devendo cada escola não agrupada/agrupamento de escolas designar um professor-coordenador para a ES (Lei n. ${ }^{\circ}$ 60/2009). A lei prevê, ainda, que a ES deve ter o acompanhamento de profissionais de saúde e devem ser estabelecidos acordos de parceria com entidades devidamente credenciadas na área da EpS/ES, para o desenvolvimento de projetos específicos (Lei n. ${ }^{\circ} 60 / 2009$ ).

Dois anos antes da legislação mais recente ter entrado em vigor, o GTES realizou uma avaliação da ES em contexto escolar (ME-GTES, 2005, 2007a, 2007b), e em março de 2014 foi publicado o relatório de avaliação sobre a aplicação da ES (Matos et al., 2014). Ainda assim, pareceu-nos 
pertinente caracterizar e avaliar o processo de implementação da ES em meio escolar numa região particular - o Algarve, tendo sido nossa intenção perceber não só qual o grau de cumprimento em termos de enquadramento legal, mas sobretudo de que forma se tem concretizado a ES em contexto escolar. Mais concretamente, quisemos perceber se a ES foi incluída no projeto educativo dos agrupamentos de escolas (AE) e de que forma tem sido implementada; identificar e caracterizar os agentes educativos que participaram no processo de implementação da ES; avaliar as parcerias estabelecidas com outras entidades credenciadas na área da EpS/ES; perceber qual a dinâmica dos Gabinetes de Informação e Apoio ao Aluno (GIAA); e perceber se a aquisição de competências e a mudança de comportamentos foram contempladas como objetivos dos programas de ES desenvolvidos pelos AE. Quisemos, também, contribuir para informar e dar suporte aos programas e intervenções de ES num contexto específico de uma das regiões nacionais, tendo em conta as limitações e os fatores que efetivamente promoveram o sucesso da ES, identificados pelos agentes educativos responsáveis pela ES.

\section{Método}

Tendo em conta os objetivos apresentados e a natureza dos fenómenos, o presente estudo insere-se no paradigma interpretativo/ qualitativo, por nos permitir considerar os significados atribuídos pelos indivíduos aos fenómenos em estudo, mais do que as suas causas (Cohen, Manion, \& Morrison, 2007). Ao considerarmos que as interações humanas recriam de modo contínuo a vida social, tal estratégia implica investigar perspetivas individuais, constructos pessoais, negociar significados e definições de situações, no contexto de uma perspetiva fenomenológica, interacionista e de interesse prático (Creswell, 2013).

Pelas suas particularidades, optámos por realizar um estudo de caso múltiplo, com recurso a técnicas qualitativas de recolha de dados (entrevista a coordenadores da EpS/ES e a um diretor de AE). A fonte direta dos dados é o ambiente natural, assumindo-se o investigador como o principal instrumento de recolha de dados (Bogdan \& Biklen, 1994). Mais concretamente, trata-se de uma investigação de tipo descritivo, em que o foco é nos processos e não tanto nos resultados ou produtos, respeitando a 
unicidade e a dinâmica dos contextos (Cohen et al., 2007; Creswell, 2013). Enquanto estudo de caso descritivo reportado a uma ou mais organizações (Yin, 2010), inclui um foco narrativo, combinando subjetividade com objetividade (Dyer, 1995, cit. por Cohen et al., 2007; Creswell, 2013).

\section{Participantes}

Os seis $A E$ que integraram este estudo foram selecionados de forma aleatória, tendo em conta a existência do $3^{\circ}$ Ciclo do Ensino Básico (CEB) e do ensino secundário e o facto de estarem localizados em municípios com número variável de residentes, de forma a abarcar diferentes realidades educativas. Por questões de confidencialidade, os $\mathrm{AE}$ serão designados por $A E 1$ e AE2, ambos situados em concelhos com menos de 40 mil residentes, e por AE3, AE4, AE5 e AE6, situados em concelhos com 40 mil ou mais residentes. Os AE 1 e 2 têm uma população escolar de 1500 e 1800 alunos, respetivamente, enquanto o AE3 tem cerca de 2000 alunos, o AE4 cerca de 2500, o AE5 cerca de 2700 e o AE6 cerca de 2900. Participaram no estudo nove sujeitos do sexo feminino (oito coordenadores de EpS/ES e um diretor de $A E)$. Inicialmente, o objetivo era entrevistar os diretores dos AE; no entanto, devido à especificidade do tema, os mesmos consideraram que seria mais adequado entrevistar os coordenadores da EpS/ES. Num dos AE, para além de termos entrevistado o coordenador da EpS/ES, o diretor mostrou-se disponível e interessado em participar. Suspendeu-se a inclusão de novos participantes quando as informações fornecidas começaram a apresentar repetição dos dados recolhidos (Denzin \& Lincoln, 1994).

Dos nove participantes, cinco são professores de Ciências Naturais e dois de Biologia, um é professor de Economia e um de Inglês/Alemão. A média de anos de serviço dos nove participantes é de 22,89 anos ( $D P=8,82$ ), e a média de anos de coordenação de EpS/ES dos sete participantes é de 7,71 anos $(\mathrm{DP}=4,75)$.

\section{Instrumentos}

Neste estudo recorremos a uma entrevista semidiretiva (Ghiglione \& Matalon, 2001), destinada a coordenadores da EpS/ES e ao diretor de AE, com a intenção de avaliar de que forma a ES foi implementada, identificando 
os agentes que participaram neste processo. Quisemos, também, avaliar as parcerias estabelecidas com outras entidades credenciadas na área da EpS/ES e identificar as estruturas de apoio.

O guião da entrevista (em anexo) foi construído com base na Lei $n .^{\circ}$ 60/2009 e na Portaria n. ${ }^{\circ}$ 196-A/2010, sendo constituído por 14 perguntas. Por motivos de garantia de fidelidade e validade do estudo, foi testado junto de três sujeitos, com experiência superior a 15 anos em funções de direção de escolas não agrupadas, na região de Lisboa, e mais de 30 anos de serviço. As questões foram apresentadas e discutidas com cada um dos sujeitos, individualmente (método da reflexão falada), tendo sido propostas algumas alterações e sugerida a introdução de novas questões.

$O$ instrumento de recolha de dados foi registado na plataforma online do Ministério da Educação e Ciência (MEC) - Monitorização de Inquéritos em Meio Escolar (MIME), e aprovado pela Direção-Geral de Educação para aplicação em meio escolar com o número de registo 0396900001.

\section{Procedimentos de recolha e análise de dados}

Após as necessárias autorizações, os dados foram recolhidos, entre fevereiro e maio de 2014, em cada AE. As entrevistas foram realizadas individualmente, por uma das investigadoras, e o tempo de realização variou entre 40 minutos e uma hora.

Após a transcrição na íntegra de todas as entrevistas realizadas, coligindo e construindo um corpus da análise (dados resultantes), recorremos a uma análise comparativa entre as indicações da legislação (Lei n. ${ }^{\circ} 60 / 2009$; Portaria n. $\left.{ }^{\circ} 196-A / 2010\right)$ e os dados das entrevistas. Para tal, tendo como base um quadro de referência a priori (guião de entrevista), definimos os seguintes indicadores: "cargo que o participante ocupa no $A E$ "; "tipo de projetos desenvolvidos pelo $A E$ na área da EpS/ES"; "ano de integração da ES no projeto educativo do AE"; "ciclos de ensino em que foi integrada a ES"; "participantes no processo de ES no $3^{\circ}$ CEB"; "critérios utilizados para designar o professor-coordenador da EpS/ES"; "tipo de formação dos professores-coordenadores na área da ES"; "disciplinas que mais participaram no projeto de ES de turma"; "tipo de entidades credenciadas na área da ES com as quais foram estabelecidas parcerias"; "tipo de apoio 
prestado pelos parceiros"; "funcionamento, parceiros e recursos disponibilizados pelo GIAA"; "estratégias para a operacionalização do projeto de ES de turma"; "tipo de avaliação do projeto de ES" e "objetivos da ES privilegiados".

Seguiu-se a construção de uma grelha de análise aberta e a definição das categorias conforme estas iam emergindo da nossa análise ao corpus (Paulos, 2014). As categorias que permitiram uma resposta direta aos objetivos definidos (unidade de registo) (da pergunta 1 à 11) foram objeto de uma análise qualitativa, a qual recorre a indicadores não frequenciais (presença ou ausência) suscetíveis de permitir inferências (Bardin, 2009). Nas categorias cujas respostas refletiram opiniões pessoais sobre o tema (da 12 à 14), contou-se o número de vezes que determinado conteúdo apareceu (unidade de numeração aritmética), seguindo-se a análise quantitativa, que permite obter dados descritivos tendo em conta a frequência de aparição de certos elementos da mensagem (Bardin, 2009). Os dados resultantes (corpus da análise) da análise de conteúdo (Bardin, 2009) foram posteriormente submetidos a procedimentos estatísticos que, pelo poder explicativo que aportavam, justificaram a sua escolha.

Todos os tratamentos estatísticos foram efetuados com recurso ao software $R$ (R Development Core Team, 2013), com o pacote gdata, tendo sido calculadas as médias e o desvio-padrão, bem como percentagens.

\section{Apresentação e discussão de resultados}

Avaliar se a Educação Sexual foi incluída no projeto educativo dos agrupamentos de escolas e de que forma foi implementada

Face aos resultados obtidos, podemos afirmar que a ES foi incluída no projeto educativo de todos os $A E$ do estudo. Ainda assim, os $A E 3$ e 4 integraram a ES apenas nos $2^{\circ}$ e $3^{\circ}$ CEB e no ensino secundário, e os restantes $\mathrm{AE}$ em todos os ciclos de ensino. Antes da publicação da Lei $n .^{\circ}$ $60 / 2009$, todos os $A E$ desenvolveram projetos na área da EpS/ES, disponibilizando Gabinetes para a Saúde dedicados ao atendimento dos alunos (AE 1, 2, 3, 4 e 5), promovendo sessões de formação/sensibilização de caráter contínuo ( $A E$ 5) e de caráter pontual ( $A E$ 4, 5 e 6), dinamizadas por agentes externos, verificando-se que a experiência adquirida nesse âmbito parece ter facilitado o processo de implementação da ES. 
No que respeita à organização e planeamento anuais da ES, de forma a cumprir as 12 horas anuais, constatámos que o projeto de ES de turma foi elaborado pelo professor-coordenador da EpS/ES (em todos os AE) e pela equipa interdisciplinar (AE 2 e 6), e partilhado com os diretores de turma, para que, em conjunto com o conselho de turma, o adaptassem de acordo com as necessidades e características de cada turma, como previsto na lei (artigo $7^{\circ}$ da Lei n. ${ }^{\circ}$ 60/2009; Portaria n. ${ }^{\circ}$ 196-A/2010). Constatámos que apenas o AE 5 não cumpriu as 12 horas previstas, uma vez que, segundo a coordenadora de $E p S / E S$, a redução da componente letiva atribuída ao coordenador não tem sido suficiente para levar a cabo o projeto da ES. De acordo com a UNESCO (2009), a grande maioria dos programas aplicados nas escolas que obtiveram resultados positivos a longo prazo incluíram 12 ou mais sessões anuais, com a duração de, pelo menos, 30 minutos.

Quanto à operacionalização da ES, percebemos que os $A E$ 1, 2, 5 e 6 procuraram integrar o projeto de ES nas várias disciplinas, de forma a que a ES fosse abordada naturalmente pelos professores, e recorreram, também, a agentes externos e à coordenadora de EpS/ES para desenvolverem atividades pontuais; no AE 4 a ES foi desenvolvida através de sessões pontuais de formação/sensibilização dinamizadas pelos psicólogos do Serviço de Psicologia e Orientação (SPO) e pela coordenadora da EpS/ES, recorrendo, também, aos parceiros, os quais dinamizaram atividades de caráter contínuo e pontual, integradas no plano anual de atividades do AE; no $A E 3$ a ES foi desenvolvida, maioritariamente, pela coordenadora da EpS/ES, que dinamizou sessões de formação/sensibilização pontuais nas turmas, e pela enfermeira, que promoveu, sobretudo, o atendimento aos alunos no GIAA.

Os resultados do presente estudo demonstraram que todos os $A E$ recorreram à coordenadora de EpS/ES para levar a cabo a ES, mas que, pelo reduzido número de horas disponíveis para a EpS/ES, apelaram, também, a agentes externos para dinamizarem ações de formação, sendo que apenas quatro $\mathrm{AE}$ contemplaram os conteúdos da $\mathrm{ES}$ de forma transversal, em todas as disciplinas, como previsto na lei. Segundo os resultados do Projeto Experimental do Programa de Promoção e Educação para a Saúde - PES, Associação para o Planeamento da Família - APF e Direção-Geral da Saúde - DGE (1999), as ações dinamizadas por agentes externos revelaram ser o 
método menos eficaz pelo seu caráter esporádico, irregular e menos responsabilizador da escola como um todo. Os mesmos autores consideraram que este tipo de atividades é mais eficaz quando combinado com a ES realizada de forma transversal, o que se constatou nos $A E$ 1, 2, 5 e 6, mas não nos $A E 3$ e 4. No entanto, apesar de ter sido referido pelos coordenadores da EpS/ES de quatro AE que o projeto da ES de turma era operacionalizado de forma transversal, os mesmos referiram que a disciplina de Ciências Naturais tem sido a mais interveniente nos projetos de ES de turma, seguindo-se a de Português, sendo que as restantes disciplinas mencionadas pelos participantes obtiveram uma percentagem reduzida (Figura 1).

\section{Figura 1 - Disciplinas que participaram no projeto de Educação Sexual} de turma

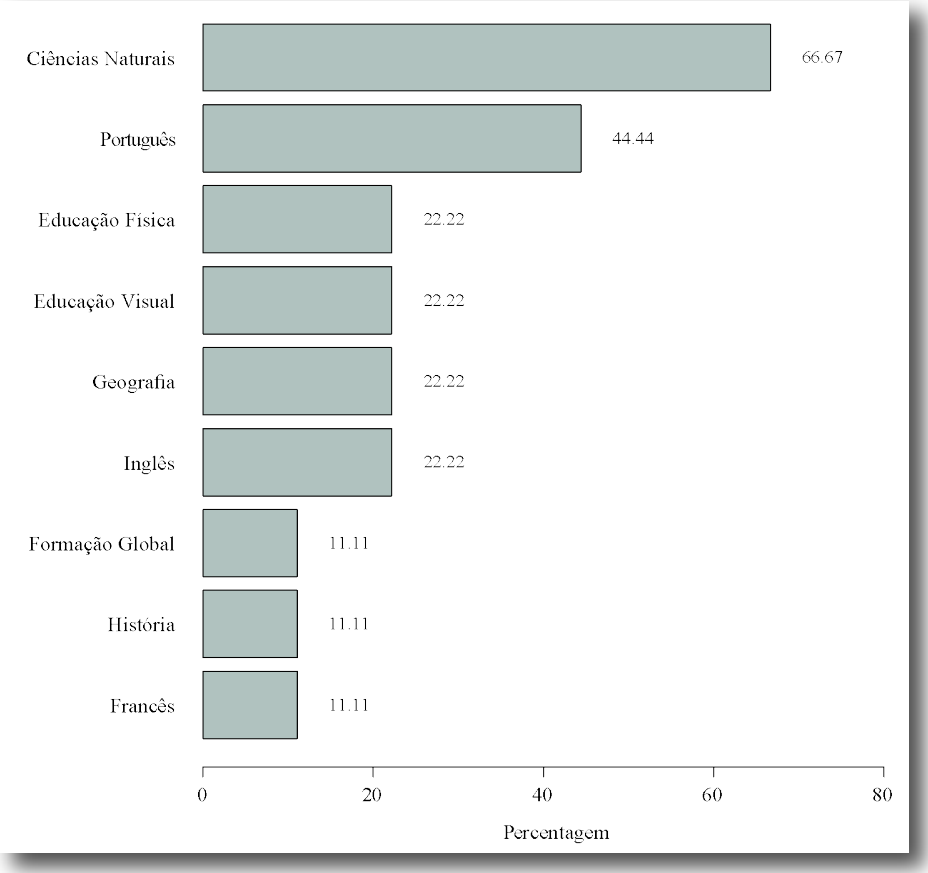

De referir ainda que, apesar de a atual lei contemplar que os conteúdos da ES devem ser desenvolvidos nas ACND (artigo 2. ${ }^{\circ}$ da Portaria n. ${ }^{\circ}$ 196-A/2010), tal não se verificou no nosso estudo, uma vez que estas 
foram extintas (Decreto-Lei n. ${ }^{\circ}$ 50/2011; Decreto-Lei n. ${ }^{\circ}$ 139/2012). Para os participantes, o seu desaparecimento acabou por comprometer a operacionalização da ES, visto que os seus temas eram, muitas vezes, abordados no âmbito da Formação Cívica. Estas áreas pretendiam promover a autonomia, a responsabilidade e o espírito crítico, sendo mais fácil abordar temas e problemas transversais às várias disciplinas, uma vez que são "de natureza transversal e integradora" e para os alunos correspondiam "a oportunidades de aprendizagem que devem ser articuladas com todas as outras" (Ministério da Educação, 2001, p. 11).

Observámos também que todos os $\mathrm{AE}$ se basearam nos objetivos mínimos da ES (artigo $2 .^{\circ}$ da Lei $n .^{\circ}$ 60/2009), adaptando os conteúdos previstos para o $3^{\circ} \mathrm{CEB}$ (quadro anexo da Portaria n. ${ }^{\circ}$ 196-A/2010) às características e necessidades de cada turma. Contudo, todos os $A E$ determinaram conteúdos prioritários, tais como as IST, a gravidez na adolescência, os métodos contracetivos, o Vírus da Imunodeficiência Humana/Síndrome de Imunodeficiência Adquirida (VIH/Sida) e os sistemas reprodutores, tendo em conta a sua pertinência na faixa etária em questão e as necessidades dos alunos. Os AE 3, 4 e 5 privilegiaram, ainda, os objetivos que visam desenvolver sentimentos e atitudes, trabalhando os afetos e 0 reconhecimento da importância dos sentimentos e da afetividade na vivência da sexualidade, bem como o treino e aquisição de competências.

Considerando a perspetiva de Frade et al. (2006) no que respeita aos objetivos da ES, constatámos no presente estudo que todos os $A E$ privilegiaram o aumento e a solidificação dos conhecimentos (IST e gravidez na adolescência, métodos contracetivos, VIH/Sida e sistemas reprodutores). Tal pode ter ocorrido devido ao facto de estes conteúdos fazerem parte do programa curricular da disciplina de Ciências Naturais no $3^{\circ} \mathrm{CEB}$, na qual, segundo o presente estudo, a ES é abordada com mais regularidade. Estes resultados permitem-nos afirmar que os $A E$ seguiram, maioritariamente, 0 modelo médico-preventivo, o qual visa a prevenção de comportamentos de risco. Não obstante, embora de utilidade evidente, este modelo não aborda as componentes emocionais e relacionais da sexualidade, sendo possível que os $A E$ que o seguiram possam, muitas vezes, confrontar-se com necessidades de formação dos jovens nestas matérias. Os resultados sugerem, ainda, que a seleção dos temas a abordar pode estar relacionada com o conforto dos professores em abordar certos temas e não tanto com os interesses e as necessidades dos alunos. 
Percebemos que a avaliação do projeto de ES tem sido realizada tendo em conta "as horas usadas na ES", "os temas abordados", "as atividades realizadas", "a opinião/avaliação dos alunos" relativamente às atividades desenvolvidas e o "número de alunos" que receberam informação através de sessões dinamizadas por agentes externos ( $A E$ 1, 2, 3, 4, 5 e 6); teve em conta, também, a contabilização das disciplinas intervenientes (AE 1, 2 e 5) e os materiais produzidos no âmbito da ES (AE 1 e 2). O AE 2 realizou a avaliação do impacto do projeto de ES na aquisição de conhecimentos e mudança de comportamentos nos alunos através de avaliação qualitativa (nível de empenho e motivação dos alunos nas atividades desenvolvidas) e quantitativa (trabalhos realizados pelos alunos; testes de avaliação de conhecimentos; inquéritos aos alunos realizados previamente à atividade e no final, para verificar mudanças de opinião e atitudes). Os restantes $A E$ realizaram uma avaliação qualitativa das atividades com base na motivação e participação dos alunos nas atividades desenvolvidas.

Estes resultados sugerem que, tendo em conta a natureza dos fatores considerados na avaliação da ES levada a cabo pelos $A E$, os processos de avaliação não têm contemplado a avaliação de conhecimentos, nem os principais objetivos da ES - a aquisição de competências e as mudanças de comportamentos. No presente estudo, apenas o $A E 2$ avaliou o impacto da $E S$ nestas dimensões, sendo que os restantes $A E$ realizaram uma avaliação qualitativa das atividades. Entendemos, à semelhança de Ramiro, Matos, e Vilar (2008), que somente através da avaliação sistemática e efetiva dos projetos de ES e do seu impacto nos conhecimentos e atitudes dos alunos será possível compreender mais e melhor os fatores que efetivamente promovem o sucesso da ES. Contudo, e na linha de pensamento de Reis (2004), parece-nos que esta avaliação só será possível a médio e a longo prazo, quando a ES estiver sistematizada nas escolas e depois de clarificar qual a dimensão pretendida quando se fala de avaliação na área da ES.

Pelo discurso dos participantes percebemos que o MEC não parece ter participado ativamente no trabalho desenvolvido no âmbito da EpS/ES, ao qual foram apontados aspetos negativos e positivos (Tabela 1). De acordo com os participantes do estudo, o MEC não tem assumido ativamente o seu papel no acompanhamento, na supervisão e na coordenação da EpS/ES (artigo $13 .^{\circ}$ da Lei n. ${ }^{\circ}$ 60/2009). Na prática, o MEC tem desempenhado 
funções no âmbito da avaliação do cumprimento da lei e não tanto no âmbito da viabilidade dos projetos de ES. Os participantes mencionaram ainda que a formação necessária para o exercício de funções na área da ES, garantida pelo MEC ( $n .^{\circ} 4$ do artigo $8 .^{\circ}$ da Lei $n .^{\circ} 60 / 2009$ ), foi sendo reduzida, fazendo com que os professores recorressem à formação interpares, especialistas convidados ou formação facultada por ONG. Nas palavras dos participantes, "o MEC parece ter-se esquecido da ES". Não obstante, foram realçadas as verbas disponibilizadas pelo MEC para a EpS/ES, através da Direção-Geral de Educação, as quais permitiram a aquisição de material para as atividades.

Tabela 1 - Opiniões sobre o papel do MEC no acompanhamento, na supervisão e na coordenação da Educação Sexual em contexto escolar, tendo em conta a frequência de respostas iguais por agrupamento de escolas

\begin{tabular}{lr}
\hline Aspetos negativos & Frequência \\
Redução do número de horas destinadas à formação de professores & 9 \\
Redução de horas letivas por disciplina & 5 \\
Falta de recursos humanos para apoiar a ES & 3 \\
Legislação desatualizada & 2 \\
Programas curriculares desajustados & 2 \\
Aspetos positivos & 3 \\
Verba disponibilizada para a EpS/ES & \\
\hline
\end{tabular}

As maiores limitações identificadas no processo de implementação da ES pelos participantes (Tabela 2) resultaram do pouco apoio do MEC, mas também das políticas educativas implementadas recentemente, tais como a redução do número de horas disponíveis para a formação de professores, a qual é exigida e necessária nesta área, e a redução de horas letivas, limitando o tempo dos professores para cumprir os conteúdos programáticos e não disponibilizando horas para a ES. Os participantes referiram, também, que o facto de os programas curriculares estarem desajustados, dificultando a integração dos objetivos da ES, e de a lei estar desatualizada no que diz respeito à prossecução das finalidades da ES comprometem a sua concretização (artigo 2..$^{\circ}$ da Portaria n. ${ }^{\circ}$ 196-A/2010). Também a falta de 
informação sobre as diferentes dimensões da sexualidade, por parte dos professores e pais, associando a ES somente à dimensão biológica da sexualidade, foi considerada pelos participantes como um entrave. Foi ainda mencionado o facto de alguns professores considerarem que os temas da ES são de caráter privado, não devendo, por essa razão, ser abordados na escola. A pouca (ou nenhuma) participação dos pais no projeto da ES foi referida como um obstáculo na concretização efetiva da ES. Estes resultados sugerem que a continuidade da ES em contexto escolar parece depender dos professores que consideram a ES fundamental para uma educação plena do aluno.

Tabela 2 - Limitações identificadas no processo de implementação da Educação Sexual, tendo em conta a frequência de respostas iguais por agrupamento de escolas

\begin{tabular}{lr}
\hline Limitações & Frequência \\
Redução do número de horas destinadas à formação de professores & 9 \\
Falta de apoio por parte do MEC & 9 \\
Falta de informação sobre as diferentes dimensões da sexualidade por parte dos & 9 \\
professores e pais & 5 \\
Redução de horas letivas & 5 \\
Professores com pouco à-vontade na área da ES & 3 \\
Poucos conhecimentos dos professores na área da ES & 3 \\
Pouca (ou nenhuma) participação dos pais no projeto de ES de turma & 2 \\
Alguns professores consideram que os temas da ES são de caráter privado & 1 \\
Alguns professores consideram precoce falar de ES com alunos do $3^{0}$ CEB & \\
\hline
\end{tabular}

Considerando os fatores anteriormente mencionados, percebemos que nos $A E$ situados em concelhos com menos residentes e, consequentemente, com menos alunos ( $A E 1$ e 2) se observaram mais fatores em comum no processo de implementação da ES, sendo que seguiram mais fielmente as recomendações da lei que regula atualmente a ES em contexto escolar. Pelo contrário, os $\mathrm{AE}$ situados em concelhos com mais residentes e com mais alunos (AE 3 e 4) demonstraram, também, mais fatores em comum no processo de implementação da ES, mas maior distanciamento 
relativamente às recomendações da legislação em vigor. Tais evidências poderão estar relacionadas com os recursos humanos, o número de horas e os recursos materiais afetos à implementação e operacionalização da ES, os quais aparentaram ser semelhantes em cada AE. Assim, parece-nos essencial que o número de alunos do $A E$ seja considerado aquando do planeamento do projeto de ES, para que sejam assegurados os recursos necessários à sua concretização de forma holística e sistemática.

Identificar os agentes que participaram no processo de implementação da Educação Sexual no $3^{\circ}$ Ciclo do Ensino Básico

No presente estudo, os resultados parecem revelar a participação das direções dos $A E$, dos docentes (nomeadamente, os de Ciências Naturais), dos alunos e dos coordenadores da EpS/ES (AE 1, 2, 3, 4, 5 e 6), de outros agentes educativos (psicólogos e enfermeiros) (AE 4 e 6) e da antiga Direção Regional da Educação (AE 6) no processo de implementação da ES. Contudo, a participação dos pais é quase inexistente, e parece associar-se apenas ao conhecimento dos objetivos, atividades e conteúdos contemplados no projeto de ES de turma. À semelhança do que revelou o estudo de Caron et al. (1993), foi referido pelos coordenadores da EpS/ES que muitos pais não se sentem à vontade para falar sobre sexualidade e que receiam não ter a informação apropriada. Acreditam, ainda, que ao abordarem com os filhos a sua sexualidade estarão a promover o início da sua atividade sexual mais cedo do que o esperado. Finger (2000) contrariava esta ideia, referindo que os estudos realizados concluíram que a ES retardava o começo da atividade sexual porque, quando bem informados, os educandos tendem a ponderar as suas atitudes e a fazer decisões acertadas sobre o seu comportamento sexual. Sabemos também que o conhecimento, as competências e a confiança dos pais para conversar com os seus filhos adolescentes sobre questões relacionadas com a ES têm enorme potencial para promover os conhecimentos e os comportamentos preventivos nos jovens, sendo que os programas de ES devem considerar uma estratégia que aumente a frequência e a eficácia de tal comunicação (Grossman, Frye, Charmaraman, \& Erkut, 2013). Para além disso, parece-nos fundamental que os pais participem nas diversas fases dos projetos de ES (Kirby, 2001; ME-GTES, 2005). 
Quanto à participação dos alunos, os resultados indicaram que estes têm sido consultados sobre os conteúdos que gostariam de ver abordados no projeto de ES de turma, que participaram nas atividades realizadas para comemorar as efemérides (e.g., Dia dos Namorados, Dia Mundial de Luta contra a Sida), e que alguns ajudaram a organizar e a dinamizar o GIAA. Foi também mencionado pelos participantes do estudo que, no geral, os alunos participaram com entusiasmo nas atividades realizadas nas sessões de ES, nomeadamente quando estas são dinamizadas por agentes externos. Contudo, importa reforçar a importância da participação dos jovens na organização, prossecução e avaliação da ES (OMS, 2010).

Os coordenadores da EpS/ES têm participado ativamente na implementação da ES nos $A E$ estudados, tendo sido nomeados em todos os AE. Os professores-coordenadores da EpS lecionavam Ciências Naturais (AE 1, 2, 3), Biologia ( $A E 4$ e 6) e Economia ( $A E$ 5), e o professor-coordenador da ES lecionava Inglês e Alemão ( $A E$ 2), constatando-se que, no geral, os professores-coordenadores tinham formação inicial na área das Ciências, Matemática e Informática. Verificou-se ainda que todos têm formação específica na área da ES, promovida, maioritariamente, pelos Centros de Formação de Escolas, mas também por Organizações Não Governamentais (ONG). Segundo o relatório do GTES (ME-GTES, 2007b), a formação nesta área não deve ser ignorada, sendo que estes Centros devem continuar a considerar a área de EpS/ES como prioritária, disponibilizando módulos de formação contínua ao corpo docente da sua área. Percebemos também que este cargo não tem sido renovado com frequência, existindo professores a ocupá-lo há 18 anos consecutivos (desde a coordenação do antigo Projeto de Educação Sexual), uma vez que os professores de Ciências Naturais surgem, à partida, como candidatos mais motivados, pelo maior conhecimento dos aspetos biológicos do corpo humano. Assim sendo, os requisitos previstos na lei (artigo $7 .^{\circ}$ da Portaria n. ${ }^{\circ} 196-A / 2010$ ) para a nomeação deste cargo não têm sido considerados. No nosso entender, a rotatividade deste cargo tornase pertinente devido à necessidade de renovar ideias e motivações, garantindo a efetiva implementação da ES (PROF 1, AE 2). Destaca-se, ainda, que as equipas interdisciplinares (artigo $8 .^{\circ}$ da Lei n. ${ }^{\circ}$ 60/2009) não foram constituídas nos $A E$ 1, 3, 4 e 5, uma vez que partiu da direção do $A E$ a decisão sobre o número de horas a reduzir na componente letiva de quem 
integra a equipa, sendo que nestes $A E$ a redução não possibilitou a sua constituição. Nos AE onde existiam estas equipas (AE 2 e 6), constatámos que são constituídas por professores de Inglês, Alemão, Ciências Naturais, Tecnologias da Informação e Comunicação e Educação Física (AE 2), e por professores de Matemática, Ciências Naturais, Educação Visual e Educação Física (AE 6). Relativamente a esta questão, os coordenadores da EpS/ES sugeriram que as direções dos $A E$ fossem sensibilizadas para a importância da ES em contexto escolar e para os fatores que mais contribuem para o seu sucesso (AE 1 e 5).

No presente estudo foi referido pelos participantes que tem sido a disciplina de Ciências Naturais a intervir mais ativamente no projeto de ES de turma, conclusões que vão ao encontro dos resultados apurados no estudo de Matos et al. (2014). Na opinião de vários coordenadores, tal pode acontecer por se acreditar, ainda, que os professores de Ciências Naturais são os mais capazes de abordar estes temas, ignorando-se o facto de que a ES não contempla apenas a dimensão biológica e científica, mas também a dimensão dos afetos, sentimentos, competências pessoais e sociais, que qualquer professor deveria estar habilitado a abordar. De acordo com Ramiro et al. (2008), os professores de Ciências Naturais revelaram mais conhecimentos e maior probabilidade de atribuir elevada importância aos vários temas da ES. No entanto, a concretização efetiva da ES implicaria que todos os professores oferecessem o seu contributo, para que todas as áreas do conhecimento participassem no seu desenvolvimento, promovendo-se a ES de forma transversal (Precioso, 2004).

Os resultados indicaram também que todos os $A E$ estabeleceram parcerias com Centros de Saúde e Hospitalares (CSH), com ONG (AE 2, 4, 5 e 6) (APF - Associação para o Planeamento Familiar; MAPS - Movimento de Apoio à problemática da SIDA; ASMAL - Associação de Saúde Mental do Algarve; APPC - Associação de Paralisia Cerebral; GAT - Grupo Português de Ativistas sobre Tratamentos de VIH/Sida), com Outros Organismos do Estado (AE 2, 3, 4 e 5) (IPJD - Instituto Português da Juventude e Desporto; SICAD - Serviço de Intervenção nos Comportamentos Aditivos e nas Dependências; CPCJ - Comissão de Proteção de Crianças e Jovens; CVP Cruz Vermelha Portuguesa), com Instituições de Ensino Superior (AE 2 e 4) (Instituto Piaget) e com Outras Entidades (AE 2) (Ordem dos Farmacêuticos). 
Estes parceiros promoveram sessões pontuais de formação/sensibilização aos alunos ( $A E$ 1, 2, 3, 4, 5 e 6) e, também, projetos contínuos (AE 2 e 4). O recurso a parceiros para dinamizarem sessões de ES, segundo a opinião de todos os participantes, prendeu-se com a falta de professores motivados e com à-vontade para abordar temas na área da ES. Não obstante, verificámos que nos $A E 3$, 4 e 5 os coordenadores da EpS/ES dinamizaram sessões de formação/sensibilização aos alunos. Os seis AE contaram, ainda, com a colaboração de enfermeiros dos $\mathrm{CSH}$, os quais prestaram apoio ao GIAA, promovendo o atendimento e o esclarecimento de dúvidas aos alunos. Estas parcerias são indispensáveis para que os alunos e a comunidade educativa desenvolvam plenamente as suas potencialidades e adquiram competências de "saber ser" e "saber fazer" (Portaria n. ${ }^{\circ}$ 196-A/2010).

\section{Identificar a existência de Gabinetes de Informação e Apoio ao}

Aluno

No presente estudo, verificámos que cinco dos seis AE tinham o GIAA a funcionar, tal como prevê o artigo $10 .^{\circ}$ da Lei $n .^{\circ} 60 / 2009$, sendo que o GIAA do AE 6 se encontrava em fase de implementação no ano letivo 2013/2014. Percebemos que os GIAA articularam a sua atividade com os CSH (AE 1, 2, 3, 4 e 5), com ONGs (AE 4) e com Outros Organismos do Estado (AE 5), e que garantiram o horário estabelecido por lei (uma manhã e uma tarde por semana, pelo menos). No entanto, cumprir a lei parece não ter sido suficiente para alcançar o propósito do GIAA, o qual deve ser um espaço dos e para os alunos, organizado com a sua participação, devendo disponibilizar prontamente informação atualizada e métodos contracetivos adequados. À exceção do $A E$ 5, encontrou-se um espaço impessoal e, segundo as perceções da maioria dos coordenadores da EpS/ES, pouco procurado pelos alunos. Os mesmos chamaram a atenção para o facto de o MEC não criar as condições necessárias para a viabilidade do GIAA, uma vez que os alunos não têm disponibilidade para o visitar por terem horários muito preenchidos $(A E 1,2,3$ e 4), e também por terem receio de serem rotulados por frequentarem o espaço, visto que existe alguma dificuldade em conseguir um espaço que garanta o anonimato (AE 1, 2 e 3). Por sua vez, os resultados do estudo de Matos et al. (2014) demonstraram que, na perspetiva dos diretores $\operatorname{dos} A E$, a adesão dos alunos ao GIAA tem sido "muito boa". Na nossa opinião, 
esta controvérsia entre as perspetivas dos diretores e dos coordenadores da EpS/ES pode refletir algum distanciamento da realidade por parte dos diretores. Este facto pode estar relacionado com a sobrecarga de tarefas administrativas a que estão sujeitos atualmente, não lhes permitindo um envolvimento mais direto e ativo no âmbito da ES, como referido no estudo de Matos et al. (2014).

Quanto aos recursos disponibilizados pelos GIAA, constatámos que foram disponibilizados kits de demonstração e prestaram atendimento aos alunos ( $A E$ 1, 2, 3, 4 e 5), cederam um espaço condigno para os alunos frequentarem $(A E 1,3,4$ e 5) e Internet ( $A E$ 3, 4 e 5), promoveram 0 esclarecimento de dúvidas através da "caixa das dúvidas" ( $A E$ 1, 4 e 5), disponibilizaram livros ( $A E 3,4$ e 5 ) e sugestões de atividades para os professores desenvolverem com os alunos ( $A E$ e 1 e), disponibilizaram métodos contracetivos ( $A E 5$ ) e folhetos ( $A E 4$ ). Percebemos que os $A E 4$ e 5 foram os que garantiram e disponibilizaram mais recursos aos alunos e que 0 $\mathrm{AE} 2$ foi aquele que menos recursos garantiu e disponibilizou, tendo em conta que não tem um espaço em condições para o efeito. Apenas o AE 5 garantiu o acesso a métodos contracetivos, sendo que os restantes coordenadores da EpS/ES alegaram não ter autorização para o fazer. Todavia, o número 8 do artigo $10 .^{\circ}$ da Lei n. ${ }^{\circ}$ 60/2009 prevê que os GIAA, articulados com os $\mathrm{CSH}$, assegurem aos alunos o acesso a métodos contracetivos adequados. Num estudo recente à população portuguesa (Deco Proteste, 2006, cit. por Ramiro et al., 2008), verificou-se que cerca de metade dos inquiridos concordou com a distribuição de preservativos em contexto escolar. Estes resultados sugerem, mais uma vez, que a concretização da ES depende, em parte, das convicções e dos valores de quem a implementa e dinamiza.

\section{Considerações finais}

Apesar das limitações, que se prendem com as características inerentes às opções metodológicas assumidas, nomeadamente no que concerne às estratégias de recolha de dados e à constituição do grupo de participantes, podemos afirmar que o estudo contribuiu para um conhecimento mais amplo e contextualizado da forma como tem decorrido o processo de implementação da ES e de como tem sido operacionalizado o projeto de turma no $3^{\circ} \mathrm{CEB}$, na região do Algarve. Foi possível, também, 
identificar os agentes educativos e os parceiros que mais participaram, bem como as estruturas existentes que apoiaram a concretização da ES. Além disso, entendemos que estes resultados contribuíram para perceber as limitações identificadas no processo de implementação e os fatores que promoveram o sucesso da ES formal nos $A E$ estudados, promovendo a melhoria e reforço dos programas e intervenções de ES.

No nosso entender, a legislação que estabelece o regime de aplicação da ES em contexto escolar (Lei n. ${ }^{\circ}$ 60/2009; Portaria n. ${ }^{\circ}$ 196-A/2010) foi cumprida no que respeita à sua integração no projeto educativo dos $A E$, na região do Algarve, bem como à carga horária estipulada. No geral, os $A E$ dispõem de um GIAA, organizado pelos coordenadores da EpS/ES, apesar de nos parecer que o espaço é utilizado essencialmente para planear as ações a desenvolver no âmbito da EpS/ES, sendo mais aproveitado pelos professores e não tanto pelos alunos. No que respeita à implementação da $E S$, percebemos que os $A E$ situados em concelhos com menos residentes e, consequentemente, com menos alunos ( $A E 1$ e 2 ) revelaram mais fatores em comum no processo de implementação da $E S$, apresentando um percurso mais próximo das recomendações da lei que regula atualmente a ES em contexto escolar, sugerindo que o número de alunos pode ter algum tipo de relação com o modo como se implementa a ES. Os resultados do nosso estudo evidenciaram, também, que a disciplina de Ciências Naturais foi o espaço curricular onde temas da ES eram abordados com mais frequência, sugerindo que a sua realização ao nível interdisciplinar e transversal não parece ser, ainda, uma realidade constatada na prática. Na mesma linha de pensamento do GTES (ME-GTES, 2005), consideramos que cada disciplina deveria procurar perceber qual o contributo a dar à EpS/ES, uma vez que todos os professores têm na sua zona de conforto tópicos que podem desenvolver na área da sexualidade.

No âmbito dos conteúdos abordados, foi privilegiado o aumento e a consolidação dos conhecimentos, numa vertente de prevenção, apesar de percebermos que estão a ser assumidas outras preocupações, como o treino de competências pessoais e sociais, sentimentos e atitudes. Ainda assim, parece-nos que, apesar de a legislação apontar para que os objetivos propostos nos programas de ES contemplem múltiplas temáticas, os $A E$ estudados seguiram, maioritariamente, o modelo médico-preventivo. Desta 
forma, parece-nos que não se tem dado espaço para trabalhar a aquisição de competências e as mudanças de comportamentos, denotando-se, também, no presente estudo, a ausência de avaliação dos projetos de ES neste âmbito. De acordo com o trabalho desenvolvido pelo GTES (ME-GTES, 2007b), a informação sobre a sexualidade é uma vertente essencial na ES, mas não é suficiente. Sobre este assunto, Ramiro et al. (2011) defendem que os programas de ES devem contemplar a aquisição das competências cognitivas e comportamentais, a avaliação da vulnerabilidade ao risco e da motivação para a mudança e os fatores situacionais que possam intervir na implementação desse comportamento/mudança, como são as normas sociais, a pressão do grupo de pares e a influência do parceiro. Para tal, acreditamos que a abordagem a seguir no âmbito da ES deve ser holística e democrática (Ramiro et al., 2008), sistemática e não pontual, devendo iniciarse antes de qualquer atividade sexual (Firestone, 1994).

Os resultados sugerem, ainda, que a continuação e o sucesso da ES em contexto escolar parecem depender das convicções e da vontade dos professores que consideram importante abordar e integrar a ES nos conteúdos disciplinares, e que as limitações à sua prossecução passam pela falta de formação, de experiência e de à-vontade dos docentes nesta área. Neste contexto, vários autores defendem que as atitudes mais positivas face à sexualidade estão relacionadas com a formação específica nesta área (Ramiro \& Matos, 2008; Zapiain, 2003). Assim, parece-nos pertinente alertar para a importância de garantir a continuidade de ações de formação na área da ES e de as Instituições de Ensino Superior assumirem a responsabilidade na formação dos futuros professores nesta área. Contudo, na mesma linha de pensamento de Reis e Vilar (2004), para que o professor se sinta motivado para levar a cabo um programa de ES que se deseja interdisciplinar, é necessário considerar algumas variáveis, para além da formação, tais como o tempo, o espaço físico e as circunstâncias para pôr em prática um programa de ES. Para além disto, importa ter em conta que a realização da ES nas escolas de forma transversal pode aumentar a quantidade de tarefas exigidas ao docente na atualidade, sendo que os obstáculos à ES podem surgir não tanto pela falta de vontade por parte dos professores em dinamizar a ES, mas pela incapacidade de responder com confiança e capacidade. 
Entendemos que, apesar das limitações já destacadas, este estudo contribuiu, não só para perceber a importância dos docentes, da sua formação e à-vontade para abordar temas no âmbito da ES, mas também para compreender a importância do envolvimento do MEC e da comunidade educativa, nomeadamente no sucesso da sua implementação e dinamização. Ao contrário do que foi demonstrado neste estudo, o MEC deve assegurar uma intervenção ativa na prossecução da ES, de forma a que os professores não se sintam "cansados" e "sozinhos" neste percurso, mas também as famílias devem envolver-se mais na educação e na relação com a escola, outro aspeto que não se observou no presente estudo. Igualmente os alunos devem desempenhar um papel mais ativo, sobretudo através do seu envolvimento no processo de ensino/aprendizagem, parecendo-nos indispensável uma abordagem pedagógica realizada em contextos curriculares e extracurriculares, numa lógica interdisciplinar, nomeadamente na restituição das ACND.

Apesar das limitações apontadas, os participantes neste estudo acreditam na concretização efetiva da ES como uma educação transversal, indispensável ao desenvolvimento pleno dos alunos, e, por isso, continuam a investir na ES por reconhecerem a sua importância na formação pessoal, social e cívica dos alunos, "promovendo o crescimento sadio, pleno e holístico do indivíduo" (PROF 2, AE 6).

\section{Agradecimentos}

O estudo relatado no texto foi financiado por Fundos Nacionais através da FCT Fundação para a Ciência e a Tecnologia no âmbito do projeto UID/SOC/04020/2013.

\section{Referências}

Bardin, L. (2009). Análise de conteúdo. Lisboa: Edições 70.

Bogdan, R., \& Biklen, S. (1994). Investigação qualitativa em educação. Porto: Porto Editora.

Canário, R. (2005). Aprender sem ser ensinado. A importância estratégica da educação não formal. In Conselho Nacional de Educação (Ed.), A educação em Portugal (1986-2006). Alguns contributos de investigação (pp. 207-267). Lisboa: Conselho Nacional de Educação. 
Caron, S., Knox, C., Rhoads, C., Aho, J., Tulman, K., \& Voloch, M. (1993). Sexuality education in the workplace: Seminars for parents. Journal of Sex Education and Therapy, 3, 200-211.

Cohen, L., Manion, L., \& Morrison, K. (2007). Research methods in education (6 $6^{\mathrm{a}}$ ed.). Londres: Routledge.

Creswell, J. (2013). Qualitative inquiry and research design. Choosing among five approaches. Londres: Sage.

Denzin, N., \& Lincoln, Y. (Ed.). (1994). Handbook of qualitative research. Thousand Oaks: Sage Publications.

Finger, W. (2000). Sex education helps prepare young adults. Network, 3, 10-15.

Firestone, W. (1994). The content and context of sexuality education: An exploratory study in one state. Fammily Planning Perspectives, 26(3), 125-131.

Frade, A., Marques, A. M., Alverca, C., \& Vilar, D. (2006). Educação Sexual na escola Guia para professores, formadores e educadores ( $5^{\mathrm{a}}$ ed.). Lisboa: Texto Editora.

Ghiglione, R., \& Matalon, B. (2001). O inquérito: Teoria e prática. Oeiras: Celta Editora.

Grossman, J. M., Frye, A., Charmaraman, L., \& Erkut, S. (2013). Family homework and school-based sex education: Delaying early adolescents' sexual behavior. Journal of School Health, 83, 810-817.

Kirby, D. (2001). Understanding what works and what doesn't in reducing adolescent sexual risk-taking. Fam Plann Perspect, 33, 276-281.

López, F. (1990). Educación Sexual. Madrid: Fundación Universidade Empresa.

López, F., \& Fuertes, A. (1999). Para compreender a sexualidade. Lisboa: Associação para o Planeamento da Família.

López, F., \& Oroz, A. (1999). Para compreender la vida sexual del adolescente. Pamplona: Verbo Divino.

Matos, M. G., Reis, M., Ramiro, L., Ribeiro, J. P., \& Leal, I. (2014). Educação Sexual em Portugal - Legislação e avaliação da implementação nas escolas. Psicologia, Saúde e Doenças, 15(2), 335-355.

Ministério da Educação - Grupo de Trabalho de Educação Sexual (ME-GTES) (2005). Educação para a Saúde: Relatório preliminar. Lisboa: Direcção-Geral de Inovação e de Desenvolvimento Curricular, Ministério da Educação.

Ministério da Educação - Grupo de Trabalho de Educação Sexual (ME-GTES) (2007a). Relatório de progresso. Lisboa: Direcção-Geral de Inovação e de Desenvolvimento Curricular, Ministério da Educação.

Ministério da Educação - Grupo de Trabalho de Educação Sexual (ME-GTES) (2007b). Relatório final. Lisboa: Direcção-Geral de Inovação e de Desenvolvimento Curricular, Ministério da Educação.

Organização Mundial de Saúde (OMS) (2010). Standards for sexuality education in Europe - A framework for policy makers, educational and health authorities and specialists. Cologne: Federal Centre for Health Education.

Paulos, L. (2014). O impacto da Educação Sexual em contexto escolar (Dissertação de Mestrado em Ciências da Educação e da Formação). Faculdade de Ciências Humanas e Sociais da Universidade do Algarve, Faro [documento policopiado]. 
Precioso, J. (2004). A Educação para a Saúde na escola: Um direito dos alunos que urge satisfazer. O Professor, 58(III), 17-24.

Programa de Promoção e Educação para a Saúde, Associação para o Planeamento da Família \& Direcção-Geral da Saúde (1999). Orientações técnicas sobre Educação Sexual em meio escolar: Contributos das equipas do projecto. Lisboa: Programa de Promoção e Educação para a Saúde, Associação para o Planeamento da Família \& Direcção-Geral da Saúde.

R Development Core Team (2013). R: A language and environment for statistical computing. Vienna: R Foundation for Statistical Computing.

Ramiro, L., \& Matos, M. G. (2008). Percepções de professores portugueses sobre Educação Sexual. Revista de Saúde Pública, 42(4), 684-692.

Ramiro, L., Matos, M. G., \& Vilar, D. (2008). Factores de sucesso da Educação Sexual em meio escolar. Educação Sexual em Rede, 3, 8-13.

Ramiro, L., Reis, M., Matos, M. G., Diniz, J., \& \& Simões, C. (2011). Educação Sexual, conhecimentos, crenças, atitudes e comportamentos nos adolescentes. Revista Portuguesa de Saúde Pública, 29(1), 11-21.

Reis, M. H. (2004). Os professores como actores da implementação da Educação Sexual nas escolas: A experiência portuguesa. Revista Eletrônica de Ciências da Educação, 3(2), s/p. Recuperado em http://189.16.45.2/ojs/index.php/reped/ article/view/544.

Reis, M. H., \& Vilar, D. (2004). A implementação da Educação Sexual na escola: Atitudes dos professores. Análise Psicológica, 4 (XXII), 737-745.

United Nations Educational, Scientific and Cultural Organization (UNESCO) (2009). International guidelines on sexuality education: An evidence informed approach to effective sex, relationships and HIVISTI education. Disponível em: http://unesdoc.unesco.org/images/0018/001832/183281e.pdf.

Vaz, J. M., Vilar, D., \& Cardoso, S. (1996). Educação Sexual na escola. Lisboa: Universidade Aberta.

Vilaça, M. (2006). Acção e competência de acção em Educação Sexual: Uma investigação com professores e alunos do $3^{\circ}$ Ciclo do Ensino Básico e do Ensino Secundário (Tese de Doutoramento) Universidade do Minho, Braga.

Vilar, D. (2002). Contributos para a história da Educação Sexual em Portugal. In A. Marques, D. Vilar, \& F. Forreta (2002), Educação Sexual no $1^{\circ}$ Ciclo: Um guia para educadores e formadores (pp. 15-23). Lisboa: Texto Editora.

Yin, R. (2010). Estudo de caso: Planejamento e métodos. São Paulo: Bookman.

Zapiain, J. (2003). A educação afectivo-sexual na escola. Sex Planeam Fam, 36, 33-8.

\section{Legislação}

Assembleia da República (2009). Lei n. ${ }^{\circ}$ 60/2009 - Estabelece o regime de aplicação da Educação Sexual em meio escolar. Diário da República, n. ${ }^{\circ} 151$, Série I, de 6 de agosto. 
Ministério da Educação e Ciência (2012). Decreto-Lei n. ${ }^{\circ}$ 139/2012 - Estabelece a eliminação da disciplina Formação Cívica. Diário da República, n. ${ }^{\circ} 129$, Série I, de 5 de julho.

Ministério da Educação (2011). Decreto-Lei n. ${ }^{\circ}$ 50/2011 - Estabelece a eliminação da disciplina Área de Projecto. Diário da República, n. ${ }^{\circ} 70$, Série I, de 8 de abril.

Ministérios da Saúde e da Educação (2010). Portaria n. ${ }^{\circ}$ 196-A/2010 - Regulamenta a Lei n. ${ }^{\circ}$ 60/2009. Diário da República, n. ${ }^{\circ} 69$, Série I, de 9 de abril.

Ministério da Educação (2000). Decreto-Lei n. ${ }^{\circ}$ 259/2000 - Regulamenta a Lei n. ${ }^{\circ}$ $120 / 99$ de 11 de agosto (reforça as garantias do direito à saúde reprodutiva). Diário da República, n. ${ }^{\circ}$ 240, Série I-A, de 17 de outubro.

Assembleia da República (1984). Lei n. ${ }^{\circ} 3 / 84$ - Educação Sexual e Planeamento Familiar. Diário de República, n. ${ }^{\circ}$ 71, Série I-A, de 24 de março.

Ministério da Educação (2001). Decreto-Lei n. ${ }^{\circ}$ 6/2001 - Aprova a reorganização curricular do Ensino Básico. Diário da República, n. ${ }^{\circ}$ 15, Série I-A, de 18 de janeiro. 
EVALUATION OF THE IMPLEMENTATION OF SEXUAL EDUCATION IN SCHOOLS IN ALGARVE - THE PERSPECTIVE OF EDUCATIONAL ACTORS RESPONSIBLE FOR HEALTH EDUCATION/SEXUAL EDUCATION

\begin{abstract}
A case study was performed under the interpretative/qualitative paradigm, with the main objective of evaluating the implementation of Sexual Education (SE) in the Algarve region (Portugal). We interviewed eight Health Education/Sexual Education (HE/SE) coordinators and one director of a cluster of schools (CS). Our results showed that all CS have integrated SE in their educational programs and that CS that are located in areas with fewer residents followed the legal recommendations more strictly. Each CS has designated a specific teacher to coordinate HE/SE and one CS did not have a supporting office. Natural Sciences were identified as the more active subject in SE. The increment and consolitation of knowledge was mostly performed on a preventive approach. The little support from the Ministry of Education and Science and the lack of training and experience, as well as the discomfort of teachers were identified as constraints in the implementation of the SE process.
\end{abstract}

Keywords

Sexual Education; Evaluation; Implementation; Coordinators; Teachers; Director

ÉVALUATION DE L'IMPLÉMENTATION DE L'ÉDUCATION SEXUELLE DANS LES ÉCOLES DE L'ALGARVE - LA PERSPECTIVE DES ACTEURS ÉdUCATIFS RESPONSABLES POUR L'ÉDUCATION POUR LA SANTÉ/ÉDUCATION SEXUELLE

Résumé

Cette étude de cas s'insère dans le paradigme interprétatif/qualitatif et son objectif c'est l'évaluation de la mise en œuvre de l'Éducation Sexuelle (ES) 
dans la région de l'Algarve (Portugal). On a conduit des interviews semidirectives à huit coordinateurs de l'Éducation pour la Santé (EpS)/ES et un directeur d'un groupe d'écoles (GE). Les résultats de l'étude suggèrent que I'ES a été intégrée dans les programmes d'enseignement de tous les GE et que les GE situés dans les municipalités avec moins de résidents ont appliqué plus précisément les recommandations dans la loi. Les GE ont été nommé des professeurs-coordinateurs pour EpS/ES et un seul GE n'avait pas de bureau d'appui. Le cours de Sciences Naturelles a été identifié comme le plus actif dans l'ES. Les GE ont favorisé le développement et la consolidation de la connaissance. Le pauvre soutien du Ministère de l'Éducation et des Sciences et la manque de formation spécifique, d'expérience et d'une mentalité ouverte, dans ce domaine, des professeurs ont été identifiés comme des limitations dans la mise en œuvre du processus de l'ES.

Mots-clé

Éducation Sexuelle ; Évaluation ; Implémentation ; Coordinateurs ; Professeurs ; Directeur

Recebido em outubro/2014 Aceite para publicação em julho/2015

i Faculdade de Ciências Humanas e Sociais, Universidade do Algarve, Portugal.

ii Centro de Investigação sobre o Espaço e as Organizações (CIEO), Faculdade de Ciências Humanas e Sociais, Universidade do Algarve, Portugal.

Toda a correspondência relativa a este artigo deve ser enviada para: Liliana Paulos, Universidade do Algarve, Campus de Gambelas, 8005-139 Faro. E-mail: lilianasspaulos@gmail.com. 


\section{Anexo - Guião da entrevista}

1. Há quantos anos ocupa o cargo de coordenador da Educação para a Saúde/Educaçăo Sexual (EpS/ES) / diretor(a) do Agrupamento de Escolas (AE)? Quantos anos tem de serviço?

2. Tem conhecimento se, anteriormente à publicação da Lei n. ${ }^{0} 60 / 2009$, o agrupamento $X$ desenvolvia projetos na área da EpS? Se sim, que tipo de projetos desenvolvia?

3. Em que ano letivo a ES foi integrada no projeto educativo do $A E X$ e em que ciclos de ensino?

4. Quem participou no processo de implementação da ES no $3^{\circ}$ Ciclo do Ensino Básico (CEB)?

5. Foi designado um professor-coordenador para a EpS/ES? Se sim, que disciplina(s) leciona? Fale-me do processo de nomeação do professor-coordenador e da respetiva formação na área da ES

6. Existe, no AE, uma equipa interdisciplinar para EpS/ES? Se sim, fale-me um pouco sobre a sua constituiçãa, a formação dos professores, etc

7. Foram estabelecidas parcerias com entidades credenciadas na área da ES? Se sim, indique o tipo de entidades e o que preveem essas parcerias.

8. Na EB $2,3 X$ existe um Gabinete de Informação e Apoio ao Aluno (GIAA)? Se sim, fale-me um pouco acerca do seu funcionamento e dos recursos que disponibiliza

9. Fale-me um pouco sobre a organização e o planeamento anuais da ES no $3^{\circ} \mathrm{CEB}$ de forma a garantir as 12 horas anuais.

10. Fale-me sobre a avaliação que têm desenvolvido no âmbito da ES

11. Quais foram os objetivos da ES que privilegiaram e porquê?

12. Qual tem sido o papel do MEC no acompanhamento, na supervisão e na coordenação da EpS/ES?

13. Desde que assumiu o cargo, como avalia o percurso e o desenvolvimento da ES no AE X?

14. Gostaria que me falasse um pouco sobre o que pensa da ES em contexto escolar, nomeadamente no $3^{\circ} \mathrm{CEB}$. 